IZA DP No. 4520

The Redistributive Effects of Tax Benefit Systems in the Enlarged EU

Clemens Fuest

Judith Niehues

Andreas Peichl

October 2009 


\title{
The Redistributive Effects of Tax Benefit Systems in the Enlarged EU
}

\author{
Clemens Fuest \\ University of Oxford, University of Cologne, \\ CESifo and IZA \\ Judith Niehues \\ University of Cologne, SOCLIFE and IZA \\ Andreas Peichl \\ IZA, University of Cologne and ISER
}

Discussion Paper No. 4520

October 2009

\author{
IZA \\ P.O. Box 7240 \\ 53072 Bonn \\ Germany \\ Phone: +49-228-3894-0 \\ Fax: +49-228-3894-180 \\ E-mail: iza@iza.org
}

Any opinions expressed here are those of the author(s) and not those of IZA. Research published in this series may include views on policy, but the institute itself takes no institutional policy positions.

The Institute for the Study of Labor (IZA) in Bonn is a local and virtual international research center and a place of communication between science, politics and business. IZA is an independent nonprofit organization supported by Deutsche Post Foundation. The center is associated with the University of Bonn and offers a stimulating research environment through its international network, workshops and conferences, data service, project support, research visits and doctoral program. IZA engages in (i) original and internationally competitive research in all fields of labor economics, (ii) development of policy concepts, and (iii) dissemination of research results and concepts to the interested public.

IZA Discussion Papers often represent preliminary work and are circulated to encourage discussion. Citation of such a paper should account for its provisional character. A revised version may be available directly from the author. 
IZA Discussion Paper No. 4520

October 2009

\section{ABSTRACT \\ The Redistributive Effects of Tax Benefit Systems in the Enlarged $\mathrm{EU}^{*}$}

How do different components of the tax and transfer systems affect disposable income inequality? This paper explores the redistributive effects of different tax benefit instruments in the enlarged EU based on two approaches. Inequality analysis based on the standard approach suggests that benefits are the most important factor reducing inequality in the majority of countries. The factor source decomposition approach, however, suggests that benefits play a negligible role and sometimes even contribute slightly positive to inequality. On the contrary, here taxes and social contributions are by far the most important contributors to income inequality reduction. We explain these partly contradictory results with the different normative focus of the two approaches and show that benefits have other aims than redistribution. Finally, our country clustering shows that the Eastern European countries do not form a distinguished group. The Central Eastern European countries group together with the Continental European countries and the Baltic States show similarities with some Southern European countries.

JEL Classification: D31, D60, H20

Keywords: inequality, redistribution, decomposition, tax benefit systems

Corresponding author:

Andreas Peichl

IZA

P.O. Box 7240

53072 Bonn

Germany

E-Mail: peichl@iza.org

\footnotetext{
*Andreas Peichl is grateful for financial support by Deutsche Forschungsgemeinschaft DFG (PE1675). We would like to thank John Roemer, Ulrich Walwei as well as participants of the 2009 SMYE and Verein fuer Socialpolitik conferences as well as seminar participants in Bonn, Cologne and Nuremberg for helpful comments and suggestions. The usual disclaimer applies.
} 


\section{Introduction}

It is one of the main objectives of the European Union (EU) to enhance economic and social cohesion both between and within member countries (Article 2 of the Treaty on European Union). Nonetheless, there are sizeable differences across member states in the levels of within country income inequality. This is true especially since the enlargements of the EU in 2004 and 2007, when in total 12 additional countries, mostly from Eastern Europe, joined the EU. Inequality is usually measured in terms of disposable income, which is determined by i) the pre-tax income distribution and ii) various redistributive policies. From a policy perspective, it is important to understand to what extent the differences in inequality levels between EU countries are driven by differences in the market income distribution and to what extent they are driven by different designs of the welfare state. With respect to the recent EU enlargement it is particularly interesting to see how the new member states compare to the well-established welfare states of Western Europe.

The analysis of income inequality, the design of the welfare state and the size of redistribution has a long tradition in economic and social science literature. Especially regarding the analysis of the development of income inequality across countries and time, a large number of empirical studies exists (see Anand and Segal (2008) for a recent overview). Due to data limitations, the development of the size of redistribution across countries and time is not as extensively analyzed as inequality. However, since the availability of comparable micro data sets there has been much progress in analyzing redistributive effects in cross-national comparison.

When assessing the overall distributional impact of different tax benefit instruments, one can generally distinguish two different approaches in the literature. The majority of micro studies measures effective redistribution of the tax benefit system by taking either the relative or absolute change of inequality measures of the pre-government and post-government income distribution (e.g., Mitchell (1991), Immervoll et al. (2005), Mahler and Jesuit (2006), Whiteford (2008)). Based on a certain income accounting framework, this approach sequentially applies different tax benefit instruments and compares it with the counterfactual distribution without the instrument in question. In the following, we will refer to this approach as the standard approach of measuring effective redistribution.

Another possibility to assess the impact of different income components such as taxes and transfers on income inequality is the factor source decomposition ap- 
proach as suggested by Shorrocks $(1982,1983)$. As total disposable income can be exhaustively decomposed into different pre-tax income sources as well as taxes, social insurance contributions and benefits, it is possible to calculate the contribution (equalizing or disequalizing effect) of each factor to overall inequality in the status quo. Here the inequality contribution of each factor component is determined simultaneously. With this decomposition approach it is not only possible to determine the impact of taxes and transfers but also the inequality contribution of self-employment and capital incomes as part of total income (e.g., Jenkins (1995), Jäntti (1997), Frässdorf et al. (2008)).

Obviously, different approaches can lead to different results, which in turn would imply different policy implications. Therefore, we use EU-SILC (Statistics on Income and Living Conditions) micro data of 2007 to systematically compare the two approaches with regard to the resulting redistributive effects of tax benefit systems. The 2007 wave is the first to provide information on both gross and net incomes for all $25 \mathrm{EU}$ member states (except Malta). Thus, we do not only investigate the redistributive importance of tax benefit instruments across countries, but also whether the results differ with respect to the underlying method. In the next step, we cluster countries according to their design of the welfare state and the importance of the pre-tax distribution. We investigate whether both approaches lead to a robust country clustering. Particularly, we identify the positions of the (Eastern European) new member states in the European inequality ordering.

Our results suggest that tax and transfer systems substantially reduce income inequality in all European countries. But the two measurement approaches described above generate very different, partly contradictory results. Inequality analysis based on the standard approach suggests that benefits are the most important factor reducing inequality in the majority of countries. The factor source decomposition approach, however, suggests that benefits play a negligible role and sometimes even slightly increase inequality. Here, taxes and social contributions are by far the most important contributors to income inequality reduction. We explain these partly contradictory results with the different normative focus of the two approaches and show that many benefits seem have objectives other than reducing disposable income inequality. With regard to the country clustering, we find that the Eastern European countries do not form a distinguished group, as suggested in the political sciences literature by, e.g., Fenger (2007). The Central Eastern European countries group together with the Continental European countries and the Baltic states show 
similarities with some Southern European countries.

The setup of the paper is organized as follows: Section 2 describes the data and methodologies used throughout the paper. In Section 3, we explain the different European welfare state designs and their distributional outcomes. Section 4 presents the results of the redistributive effects of tax benefit instruments based on the standard and decomposition approach. Section 5 reports the results of our hierarchical cluster analysis. Section 6 concludes by summarizing the main results and discussing their implications.

\section{Data and methodology}

\section{$2.1 \quad$ Data}

The EU-SILC (European Union Statistics on Income and Living Conditions) micro data set provides harmonized cross-sectional and longitudinal multidimensional micro data on income and social exclusion in European countries. Since 2005, the dataset covers the EU-25 member states (except Malta), plus Norway and Iceland, and it is the largest comparative survey of European income and living conditions. Our analysis is based on the 2007 EU-SILC wave which is the first wave with gross income information for all 26 countries.

For our analysis of the impacts of different sources of income it is used that individual income data can be split into different categories. These are factor incomes (earnings, income from self-employment and capital incomes), income taxes, social security contributions (employer and employee) and social transfers. In order to make incomes comparable across countries, we adjust national income amounts by the multilateral current purchasing power parities provided by Eurostat. Throughout the analysis, we use equivalized incomes to compensate for different household structures and possible economies of scales within households. ${ }^{1}$

In our application, overall equivalized disposable household income (DPI) is exhaustively decomposed into its equivalized components: factor income, income taxes, social insurance contributions, social benefits and public pensions, based on the fol-

\footnotetext{
${ }^{1}$ For each person, the equivalized (per-capita) total net income is its household total net income divided by the equivalized household size according to the modified OECD scale, which assigns a weight of 1.0 to the head of household, 0.5 to every household member aged 14 or more and 0.3 to each child aged less than 14. Summing up the individual weights gives the household specific equivalence factor.
} 
lowing identity:

$D P I=\underbrace{(\text { original income }+S I C \text { employer })}_{\text {factor } \text { income }}-$ taxes $-S I C+$ benefits + pensions

Note that our concept of factor income includes social insurance contributions paid by the employer as they can be very different across countries. We also consider the role of public pensions separately because one can argue that public pensions are not really part of the redistributive system but should rather be seen as deferred earnings or the result of compulsory savings. This function of public pensions is particularly true for countries which apply insurance-based systems. Furthermore, the analysis only allocates those taxes and benefits that can reasonably attributed to households. Therefore, corporate taxes as well as some types of government expenditures such as expenditure on defense are not considered. Due to data limitations, indirect taxes and in-kind benefits can not be taken into account, either.

\subsection{Inequality measurement}

Consider a population of $n$ persons (or households), $i=1, \ldots n$, with $x_{i}$ as the income of individual $i, \bar{x}$ be the average income and a population weight $w_{i}\left(N=\sum_{i=1}^{n} w_{i}\right)$. Following Atkinson (1970) and Kolm (1969), a relative measure of inequality can be derived from a relationship between inequality, mean income and social welfare as:

$$
I=1-\frac{W(\mathbf{x})}{\bar{x}}
$$

where $W(\mathbf{x})$ is the average or mean social welfare function (see Maasoumi (1999)). The Generalized Entropy (GE) class of inequality indices (Shorrocks (1980)) is given by:

$$
I_{\alpha}=\frac{1}{\alpha(\alpha-1)} \int_{0}^{\infty} \frac{x_{i}}{\bar{x}}\left[\left(\frac{x_{i}}{\bar{x}}\right)^{\alpha}-1\right] d F
$$

where $F$ is the $C D F$ of income and $\alpha$ being a parameter indicating the sensitivity towards a particular part of the income distribution. ${ }^{2}$ The discretized formula of

${ }^{2}$ See, e.g., Cowell and Kuga (1981). The more positive (negative) $\alpha$ is, the more sensitive $I_{\alpha}$ is to changes at the top (bottom) of the income distribution. 
the GE family used for empirical applications is given by

$$
I_{\alpha}=G E(\alpha)=\left\{\begin{array}{cc}
\frac{1}{\alpha(\alpha-1)}\left(\sum_{i=1}^{n}\left[\frac{w_{i}}{N}\left(\frac{x_{i}}{\bar{x}}\right)^{\alpha}\right]-1\right) & , \alpha \in R-\{0,1\} \\
\sum_{i=1}^{n} \frac{w_{i}}{N} \log \frac{\bar{x}}{x_{i}} & , \alpha=0 \\
\sum_{i=1}^{n} \frac{w_{i}}{N} \frac{x_{i}}{\bar{x}} \log \frac{x_{i}}{\bar{x}} & , \alpha=1
\end{array}\right.
$$

$G E(0)$ is also known as the mean log deviation and $G E(1)$ as the Theil index (see Theil (1967)). The GE measures of inequality can be interpreted in an economic way (Dahlby (1987)) using the Harsanyi $(1953,1977)$ framework which is a particular form of utilitarianism based on the veil of ignorance and equiprobability assumption (expected utility: $E U=\frac{1}{n} \sum U\left(x_{i}\right)$ with $U$ a Neumann-Morgenstern utility function with $U^{\prime}>0$ and $U^{\prime \prime}<0$ ). Using a constant relative risk aversion (CRRA) utility function it has been shown that

$$
I_{\alpha}=\frac{U(\bar{x})-E U}{\bar{x} U^{\prime}(\bar{x})} \frac{1}{1-\alpha}
$$

where $\frac{U(\bar{x})-E U}{\bar{x} U^{\prime}(\bar{x})}$ is an approximation to the relative risk premium divided by the coefficient of relative risk aversion in the Harsanyi framework.

\subsection{Standard accounting approach}

To determine the effective distributional impact of different tax benefit instruments, we will first use what we call the standard approach of analyzing the distribution and redistribution. For this approach we have to define different income concepts at different stages of redistribution. Following Mitchell (1991) and Whiteford (2008), among others, we apply an accounting framework for household income which is illustrated in Figure 1. Accordingly, income from wages and salaries, self-employment, investment incomes and in our case also employer's social contributions sum to "factor income", the inclusion of state retirement pensions then gives "market income". Market income plus all different types of cash benefits accounts to "gross income", subtracting personal income taxes gives post-tax income and finally subtracting social insurance contributions results in "cash disposable income", respectively. All income concepts are based on equivalized incomes in order to account 
for different household structures. With the accounting framework, a number of measures of the redistributive impact of the tax benefit system can be constructed by comparing inequality measures at the different stages of household income. For instance, the relative redistribution achieved by social benefits equals the percentage change between the inequality of equivalent market income and equivalent gross income:

$$
\frac{G E(\alpha)_{\text {Market }}-G E(\alpha)_{\text {Gross }}}{G E(\alpha)_{\text {Market }}}
$$

The impact of taxes is evaluated by comparing the inequality of the distribution of equivalized gross incomes and post-tax incomes and so on.

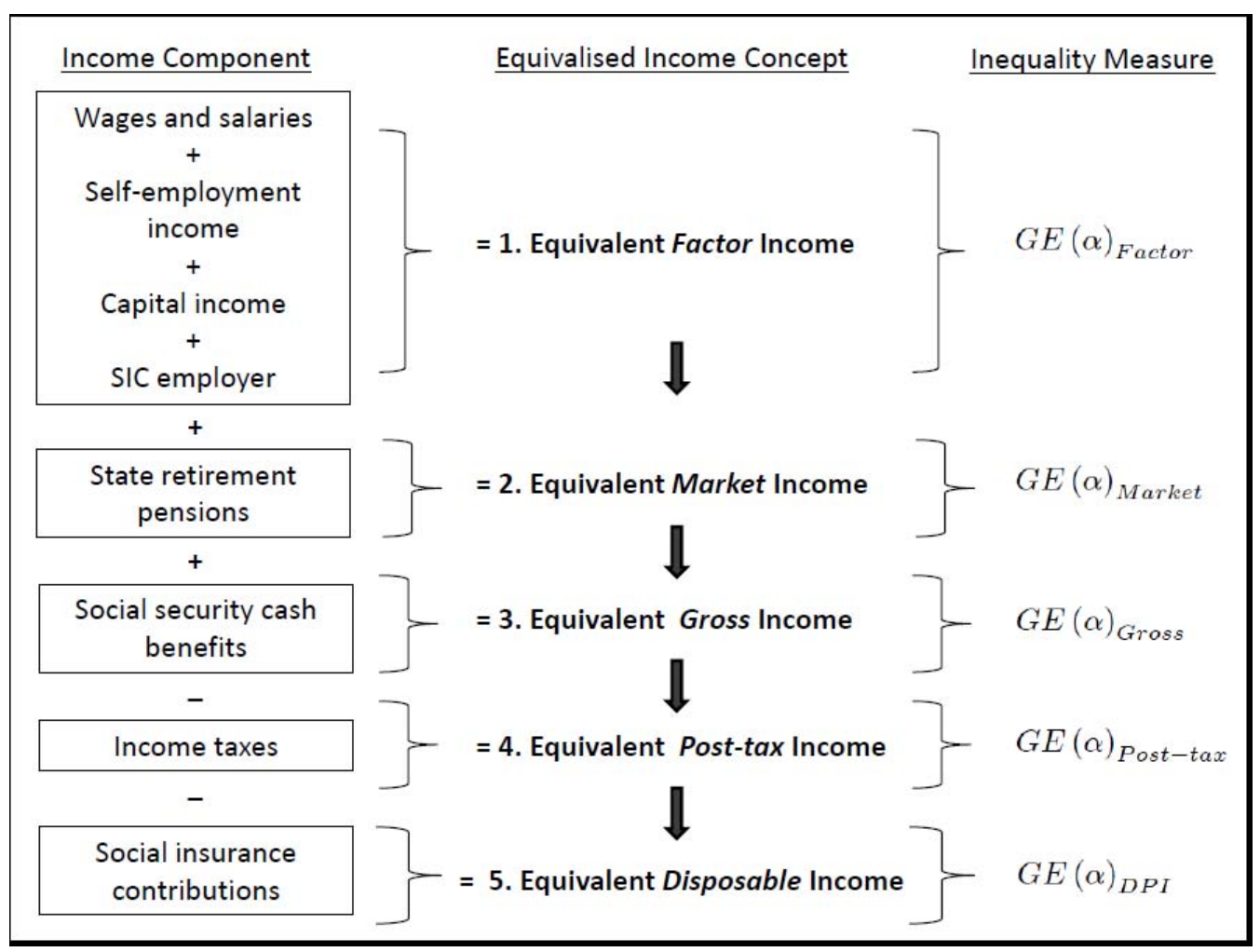

Figure 1: Income Accounting Framework

However, the framework is static and linear which implies a number of limitations. For example, there are no interactions between the different stages of redistribution. In reality, however, in some countries benefits might also be taxable. By first adding benefits to factor income, we necessarily overestimate the redistributive effects of benefits in such countries (Ferrarini and Nelson (2003); Mahler and Jesuit (2006)). Due to this sensitivity of the redistributive measures with regard to the 
definition of pre-instrument income, Immervoll et al. (2005) follow a slightly different approach which we also apply as a robustness check of our results. For each tax or benefit they start from the hypothetical situation without the instrument in question (DPI - instrument) and ask by how much inequality is reduced by introducing it.

\subsection{Factor source decomposition approach}

As total income is usually composed from several sources, it is useful to express total inequality as the sum of these factor's contributions (Shorrocks $(1982,1983)$ ). The exact decomposition procedure depends on the measure of inequality used, but whichever measure is used must naturally be decomposable and, given the large number of income sources, it must be defined for zero incomes. In practice, the easiest measure to decompose in this way is $\mathrm{GE}(2)$ which can also be expressed as half the squared coefficient of variation $C V$ :

$$
\begin{aligned}
G E(2) & =\frac{1}{2}\left(\sum_{i=1}^{n}\left[\frac{w_{i}}{N}\left(\frac{x_{i}}{\bar{x}}\right)^{2}\right]-1\right) \\
& =\frac{1}{2}(C V)^{2}=\frac{1}{2}\left(\frac{\sqrt{\operatorname{Var}(x)}}{\bar{x}}\right)^{2}=\frac{1}{2} \frac{\operatorname{Var}(x)}{\bar{x}^{2}}
\end{aligned}
$$

Suppose total income $X$ can be written as the sum of $f=1, \ldots, K$ different income sources $x_{f}: x=\sum_{f=1}^{K} x_{f}$ and $\rho_{f}$ is the correlation between $x$ and $x_{f}$ and $\mu_{f}=\frac{\bar{x}_{f}}{\bar{x}}$ is is $f^{\prime}$ s factor share.

$$
I_{2}=G E(2)=\sum_{f=1}^{K} S_{f}=\sum_{f=1}^{K} s_{f} I_{2}=\sum_{f=1}^{K} \rho_{f} \mu_{f} \sqrt{G E_{2} G E_{2}^{f}}
$$

where $G E_{2}^{f}$ denotes the inequality for factor source $f$ and $S_{f}$ the (absolute) contribution of factor $f$ to total inequality. Note that income source $f$ provides a disequalizing effect if $S_{f}>0$, and an equalizing effect if $S_{f}<0 . \quad s_{f}=\frac{S_{f}}{I}$ is the relative contribution of $f$ to total inequality and indicates the importance of $f$. 


\section{$3 \quad$ Welfare state designs in Europe}

\subsection{Welfare State Typologies}

As we are interested to classify the European countries into groups with certain characteristics, we almost necessarily have to refer to the famous welfare state typologies of the political science literature. The grouping of countries according to these typologies will be the reference point in the following analysis. Although all European countries have an individual design for their tax benefit system, it is possible to classify the countries into different welfare state regimes with similar institutional structures. The classical typology of welfare states goes back to Esping-Andersen (1990) who differentiates between three types of welfare states: conservative (Continental Europe), social-democratic (Nordic Europe) and liberal (Anglo-Saxon). Ferrera (1996) further adds a fourth category (Southern or Mediterranean) to this typology. ${ }^{3}$ The main conceptional features of these welfare state types are summarized in Table 1.

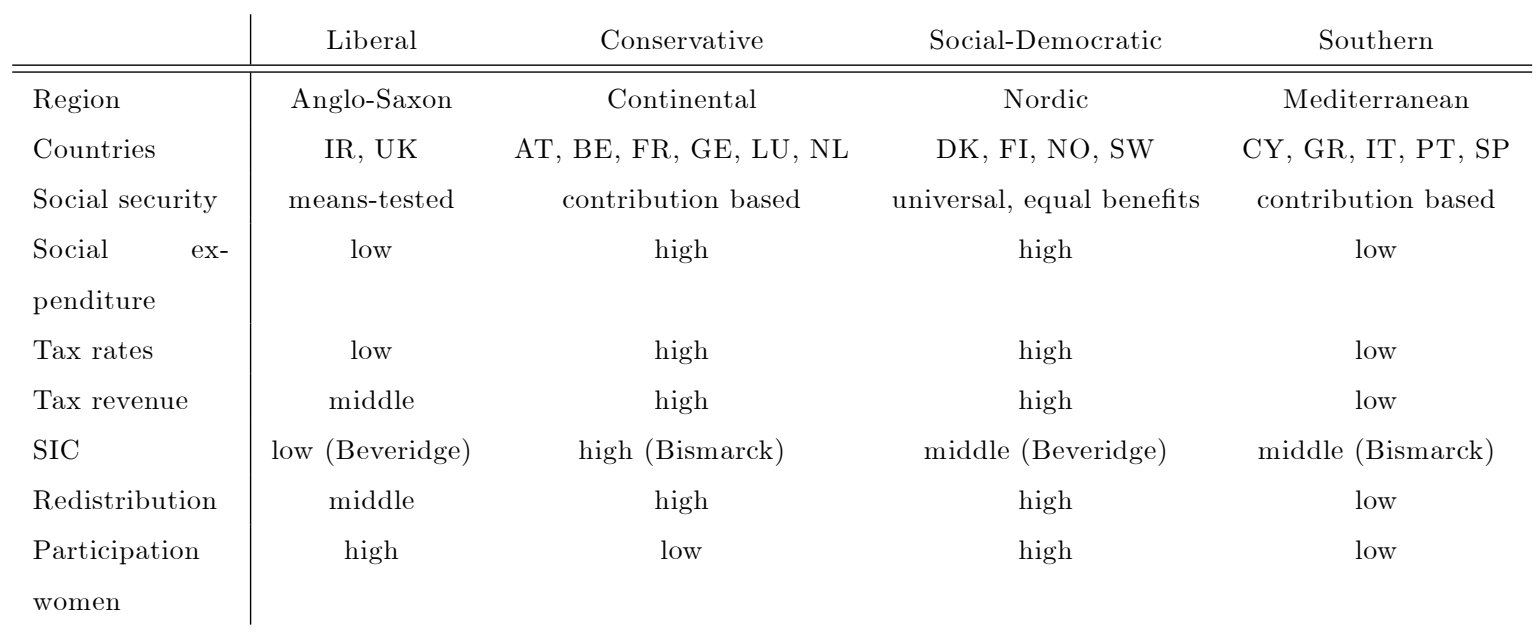

Table 1: Typology of welfare states

Anglo-Saxon countries ("liberal" welfare states) provide a minimum level of social protection (minimal subsistence level) based on universal, mean-tested benefits. People are encouraged to work (e.g. through the working families tax credit) and labor force participation is high. Tax rates and social insurance contributions are rather low. The state encourages private insurance systems through tax exemptions.

\footnotetext{
${ }^{3}$ See Arts and Gelissen (2002) for an overview. In Esping-Andersen (1990), these countries are treated as immature conservative welfare states.
} 
In this regime, market institutions are preferred to state interventions. Continental countries ("conservative" or "corporatist" welfare states) 4 use benefits that depend on the history of paid contributions (rather than on the actual need for the benefit) and aim at replicating the former income of employees (Bismarckian system). These generous schemes are financed through rather high compulsory contributions. Further on, high taxes ensure a rather high level of redistribution through various other public instruments. Nordic countries ("social-democratic" welfare states) apply even higher taxes but lower contributions for a similarly high level of redistribution. However, they use universal benefits with equal amounts for every citizen, i.e. not depending on the contribution history (Beveridgean system). These systems aim at providing a high level of social protection while simultaneously encouraging a high labor force participation through various instruments of active labor market policies and the provision of extensive child care. Mediterranean countries ("Southern" welfare states) provide a rather low level of social security (comparable to the Anglo-Saxon countries) based on low levels of taxes and redistribution. However, they also use contribution-based Bismarckian social insurance systems providing benefits depending on the level of previously earned income (like the Continental countries).

As we specifically look at the new EU member states we are interested in attempts to integrate these within the traditional welfare state typology. In fact, there are several authors in the political and social science literature who try to apply the welfare regime typology to Eastern European countries. Deacon (1993), for example, labeled these countries as 'post-communist conservative corporatist' and expected that they will form a distinct group in the welfare state typology. EspingAndersen (1996) rejected this idea of a 'new' welfare state category and argued that the differences between these countries and the traditional welfare states were only of transitional nature. More recently, Deacon (2000) and Ferge (2001), again support the view of a separated welfare state group. Fenger (2007) then applied a hierarchical cluster analysis based on a series of variables describing characteristics of governmental programmes, social situation and political participation to analyze if the post-communist welfare states of Central and Eastern Europe can be integrated in the traditional welfare state typology. His analysis suggests that the Eastern European welfare states can be clearly distinguished from the traditional

\footnotetext{
${ }^{4}$ The "conservative" model origins from the influence of the Catholic Church and is further on characterized by the fostering of traditional family structures.
} 
European welfare states.

These typologies stem from the political and social sciences literature. They are based on the conceptional design of the welfare states and use macro level variables to group the countries. It is also possible to apply this typology to economic outcomes as well. In the following sections, the outcome of the welfare state in the EU member states is analyzed with respect to several economic indicators, such as income inequality, redistribution and the composition of household income. We will then in Section 5 perform a hierarchical cluster analysis based on these micro level outcome variables in order to group the European countries and check (a) whether the classical typology for Western Europe is confirmed with this approach and (b) where the new member states fit in.

\subsection{Income Distribution and Redistribution}

The previous paragraph explained the welfare state typology from the political and social science literature which is based on the conceptual design of the welfare state. Now we look at the income distribution and overall redistribution as an outcome of the welfare state, to illustrate the variation in overall inequality levels and redistribution across EU member states. In this section, we use the Gini coefficient as our measure of inequality because of its readily intuitive interpretation and its popularity in comparable micro studies.

The variation in inequality levels in factor incomes (green + orange + blue bar), market incomes (green + orange bar) and disposable income (green bar) is also illustrated in Figure 2, where countries are sorted in ascending order of the inequality in disposable incomes. The red and blue areas of the Figure also show the very different extent of redistribution schemes across EU member states, here illustrated by the absolute difference in Gini coefficients. Overall redistribution is particularly high in the Nordic countries, some Continental countries, Hungary and Slovenia which achieve substantially better equality rankings in disposable income as opposed to factor income. It is rather low in Cyprus and Iceland, as well as in the Baltic States.

Looking at the inequality of factor incomes, huge disparities among the European countries emerge, with Gini coefficients ranging from 0.38 in Iceland to 0.54 in Portugal. Factor income inequality is comparatively high in the Anglo-Saxon countries as well as in Lithuania, Germany, Greece, Portugal and Hungary (>0.50). Rather 
low inequality levels can be found in Cyprus, Iceland, the Slovak Republic and Slovenia. Therefore, with regard to factor income inequality we cannot identify the welfare state typology outlined above. Particularly within the group of Eastern European countries there are substantial differences. The group encompasses countries with very high market inequality such as Hungary and Poland but also countries with comparatively low market inequality such as the Slovak Republic and Slovenia. The difference between the Gini coefficients of factor income and the ones of market income demonstrates the different strength of the redistributive character of pensions across European countries. It emerges, that pensions have huge redistributive power in the Continental countries such as France, Germany and Austria, who now achieve a substantial higher rank regarding the equality of incomes. This is also true for Poland and the Czech Republic. On the other hand the inclusion of pensions leads to a significant lower equality ranking of the Baltic states and Denmark.

Looking at the inequality of equivalized disposable income (DPI), first of all, it should be noted, that post-government inequality is significantly lower than the pre-government inequality, indicating a substantial degree of redistribution in all countries. Also, the ranking of countries in transition from factor to disposable income changes substantially. Here the group of Nordic countries can be identified with very low inequality levels (around 0.25) and also the Central Eastern European countries Slovenia, the Slovak and the Czech Republic display low disposable income inequalities. On the other hand, the distribution of post-government income is comparatively unequal in the Baltic, Southern and Anglo-Saxon countries $(>0.30)$.

Whereas the factor income inequality suggests a very heterogeneous country clustering, with regard to disposable income inequality, the importance of public pension schemes and overall redistribution, for the EU-15 countries we find a very similar country clustering as suggested by welfare state typology outlined above. However, the Eastern European member states do not really form a homogeneous group of countries. On the one hand, there are the Baltic States which are characterized by high factor income inequality, low redistribution and high inequality in disposable incomes. They show some similarities with the Southern European countries, still, their level of redistribution is substantially lower. Hungary and Poland show high factor income inequalities, however, combined with more extensive redistribution schemes and therefore comparatively lower inequality in disposable incomes. The other countries Slovenia, the Slovak and Czech Republic represent low inequality in factor incomes, above-average redistribution and very low inequality in disposable 


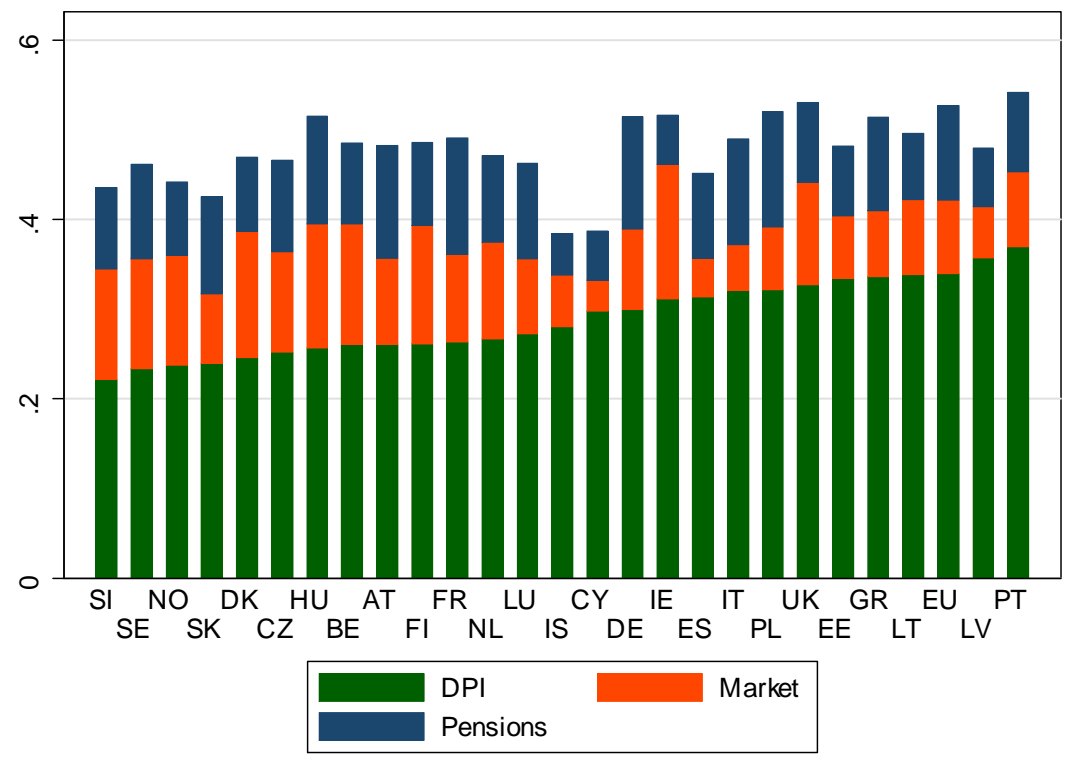

Figure 2: Gini Income Inequality and absolute Redistribution Source: Own calculations based on EU-SILC.

incomes. Therefore, with regard to inequality and overall redistribution levels, they show similar characteristics as the Nordic and Continental countries.

\subsection{Composition of household income}

As a next step we investigate in how far the importance of different components of the redistributive system varies across European countries. Figure 3 illustrates the composition of total disposable income in terms of original factor income, income taxes, social contributions, cash benefits and public pensions. We also show the importance of employer's social contributions in disposable income separately in order to visualize our concept of factor income. All incomes are equivalized. It should be noted that this perspective does not allow to identify government budget deficits or surpluses because major parts government spending and financing are not considered. According to Immervoll et al. (2005), results as in Figure 3 can be interpreted as showing how much factor income is necessary to achieve a certain level of disposable income and how much is deducted by taxes and contributions and added by benefits. If the share of factor income is around $100 \%$, then the state approximately 'gives' the same amount of benefits as he 'takes' in form of taxes and 
contributions. $^{5}$

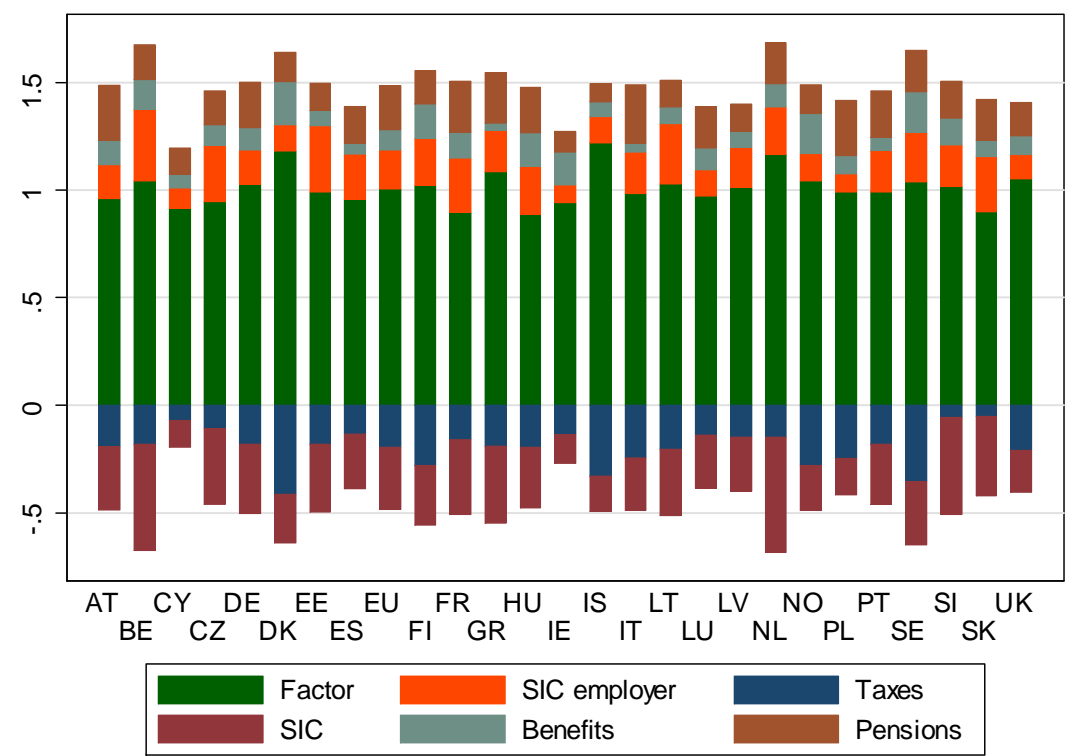

Figure 3: Factor Shares of Tax Benefit Instruments Source: Own calculations based on EU-SILC.

If we look at factor income without the social contributions of the employer, the majority of countries reveals shares in disposable income close to $100 \%$. The share of factor income is significantly larger than $105 \%$ only in Denmark, Iceland and the Netherlands, which means that in these countries the sum of deductions outweighs the sum of benefits. In Cyprus, France, Hungary and the Slovak Republic the share is less than $95 \%$, therefore on average people receive more benefits than they pay as contributions and benefits. If we consider the social contributions by the employer as part of the factor income, in all countries except Cyprus the share of factor income is significantly higher than $100 \%$. Also, the economic weight of employer's social contributions varies substantially across countries: From a share of $8.3 \%$ in Ireland to $33.2 \%$ in Belgium. With respect to the overall importance of the other income sources, total social contributions (SIC) make up a greater proportion of equivalized disposable income than income taxes in almost all countries. On average their share in disposable income is about 10 percentage points higher. Exceptions are the Nordic countries and Poland where income taxes play a more important role. The high

\footnotetext{
${ }^{5}$ Note that indirect taxes are not taken into account here. This explains why it is possible that the share of factor income in overall income may be below $100 \%$.
} 
share of social contributions may seem surprising but is explained by the fact that contributions include both, employer and employee contributions. On the benefit side, with an average share of $18 \%$ the economic weight of public pensions exceeds the importance of the rest of social benefits (on average 10\%). The opposite is true only in Denmark, Ireland and Norway. Also, Figure 3 suggests that taxes generally have a higher economic weight than social benefits. Here the only exceptions are Ireland, Slovenia and the Slovak Republic. Looking at the importance of particular income components across countries, the share of public pensions in disposable income is particularly high in some Continental countries (Austria, France, Germany) as well as in the Southern European countries Italy, Greece and Portugal (>20\%). They reveal low importance in Iceland, Ireland, Cyprus and the Baltic States. Social benefits are most important in the Nordic countries, but also in Hungary and Ireland $(>15 \%)$. They only make up a small part of disposable income in Southern European countries, which could also be expected from the welfare state typology. With regard to the burden side, the share of taxes is particularly high in the Nordic countries and Iceland and it is low in the Central Eastern European countries Slovak Republic, Slovenia and the Czech Republic as well as in Cyprus. Social contributions, on the contrary, are most important in the Continental countries such as Netherlands, Belgium, France and Germany, as it is also suggested by the welfare state typology outlined above. Their share is also relatively high in Slovenia, the Slovak and Czech Republic, whose share of income taxes is rather low.

Overall, the importance of different tax benefit components as measured by the micro composition of disposable income again suggests a similar clustering for the EU-15 countries, as suggested by the political and social science welfare state typologies. But again, the Eastern European countries do not seem to form a homogeneous and distinct group. With regard to the importance of tax benefit components in disposable income, Slovenia, the Slovak and Czech Republic reveal similarities, as does the group of the Baltic states. Poland and Hungary do not really fit into either of these two groups but rather group together with some traditional EU-15 welfare states. However, this analysis only considers the economic importance of tax benefit instruments in disposable income and does not take into account their particular distribution across households and therefore their redistributive impact on the distribution of incomes. This is what the following section deals with. 


\section{Inequality Contribution of Tax Benefit Instru- ments}

In this section, we look at the redistributive importance of the different tax benefit instruments across countries. To determine the redistributive impact of tax benefit instruments we need an inequality measure which is naturally decomposable. As outlined in Section 2, we refer to the GE measures of inequality. More specifically, we use the $\mathrm{GE}(2)$ because it is naturally decomposable and also defined for zero incomes. Furthermore, we apply two different approaches to measure the redistributive impact of taxes and benefits. First, we use the standard approach of distributional analysis which bases on a sequential accounting framework. Second, we apply the factor source decomposition approach as suggested by Shorrocks (1982, 1983) which determines the contribution of each tax benefit instrument to inequality in disposable incomes simultaneously. Finally, we compare the results and discuss the differences.

\subsection{Standard Accounting Approach}

To analyze the redistributive impact of tax benefit instruments based on the standard accounting approach, we first compute the GE(2) inequality measures for the different income concepts as illustrated in Figure 1. The results are presented on the left hand side of Table 2. By taking the percentage change between each of the consecutive inequality measures, we then compute the relative redistributive effect of the different tax benefit instruments. When comparing the GE(2) inequality measures with the Gini coefficients in Section 3, there are some important differences in the rankings of the countries. Particularly for the GE(2) inequality in disposable income it stands out that Denmark and Finland - which could be considered as rather equal with regard to the Gini Coefficients - now belong to the group of unequal countries. In addition, the Anglo-Saxon countries, Iceland, Cyprus and Estonia now achieve worse equality rankings. On the other hand, the Southern countries Spain, Greece and Italy display relatively more equal distributions of income, when using the $\mathrm{GE}(2)$ inequality measure. It might seem surprising that the inequality in disposable income in the Nordic countries such as Denmark and Finland is higher than in Italy and Spain. The reason for the difference is the fact that the GE(2) measure 
is particularly sensitive to changes at the top of the income distribution. ${ }^{6}$

However, here we are not interested in the overall redistributive effect of the tax benefit system as a whole, but in the redistributive importance of the main tax benefit instruments, such as public pensions, social benefits, incomes taxes and social insurance contributions. The amount of redistribution achieved by a certain tax benefit instrument is measured as the percentage change between two consecutive income concepts as suggested by Figure 1. The results are presented at the right hand side of Table 2, which shows the results of the redistributive effects of different tax benefit instruments for 26 European countries.

Regarding the overall redistributive importance of the different instruments, it first becomes obvious that public pensions are responsible for most of the reduction in income inequality of factor incomes. Exceptions are the Anglo-Saxon countries as well as Denmark and Norway. With respect to the other redistributive instruments, in half of the countries benefits play a more important role than income taxes, in the other countries it is the other way round. Also, the results suggest that social contributions are least important in redistributing income in almost all EU member states. In some countries the inclusion of social contributions even leads to an increase in income inequality implying a regressive incidence. Only in Slovenia contributions play the most important role in redistributing income. In Belgium, France, Lithuania and Poland they are more important than income taxes. With respect to the redistributive importance of single welfare state components across countries, public pensions are particularly important in the Continental countries (France, Austria and Germany) as well as in the Slovak Republic, Poland and Italy (around 40\%). They lead to comparatively low inequality reductions in Cyprus, Iceland, the Anglo-Saxon countries and in the Baltic States. Benefits have high redistributive effects in the Nordic countries, Ireland and Hungary, the opposite is true for the Southern European countries and the Baltic States. Inequality reduction induced by income taxes is relatively high in the UK, Hungary and Italy (>25\%), and low in Poland, Iceland and Cyprus and Denmark $(<10 \%)$. Finally, social contribu-

\footnotetext{
${ }^{6}$ There are more observations at the very top of the distribution in the data for the Nordic countries and the spread of these observations is also larger. In order to tackle this problem we applied top-coding and trimming to the data at the top and recomputed all measures. The ranking of the countries with respect to the overall level of inequality changes into the direction of the results reported for the Gini coefficient in Section 3.2. The results for the redistributive effect as well as the inequality contributions in the next section, however, remain qualitatively the same. Therefore, we decided to report the results for the uncoded data as any coding is always somewhat arbitrary.
} 
tions have high redistributive effects in Slovenia, France, Belgium and Hungary. On the other hand they lead to substantial increases in inequality in Germany, Cyprus, Estonia and Iceland $(<-10 \%)$.

\begin{tabular}{|c|c|c|c|c|c|c|c|c|c|}
\hline & \multicolumn{5}{|c|}{ GE(2) Inequality } & \multicolumn{4}{|c|}{$\begin{array}{l}\text { Redistributive Effects of Instruments } \\
\qquad \% \text { change in } \operatorname{GE}(2)\end{array}$} \\
\hline & Factor & Market & Gross & Post-tax & DPI & Pensions & Benefits & Taxes & SIC \\
\hline $\mathrm{EU}$ & 0.64 & 0.44 & 0.37 & 0.30 & 0.31 & 31.80 & 14.92 & 18.31 & -1.32 \\
\hline $\mathrm{AT}$ & 0.47 & 0.29 & 0.23 & 0.19 & 0.16 & 39.20 & 20.57 & 18.11 & 11.95 \\
\hline $\mathrm{BE}$ & 0.42 & 0.29 & 0.22 & 0.19 & 0.15 & 31.75 & 23.44 & 11.37 & 20.87 \\
\hline CY & 0.38 & 0.34 & 0.32 & 0.29 & 0.32 & 10.09 & 6.35 & 9.33 & -12.38 \\
\hline $\mathrm{CZ}$ & 0.45 & 0.30 & 0.24 & 0.19 & 0.17 & 33.40 & 18.41 & 22.88 & 7.48 \\
\hline $\mathrm{DE}$ & 0.53 & 0.33 & 0.27 & 0.23 & 0.26 & 38.05 & 19.00 & 14.69 & -13.65 \\
\hline DK & 0.62 & 0.47 & 0.33 & 0.30 & 0.28 & 24.87 & 30.17 & 9.52 & 4.22 \\
\hline $\mathrm{EE}$ & 0.70 & 0.54 & 0.50 & 0.42 & 0.46 & 22.74 & 8.44 & 15.81 & -11.44 \\
\hline $\mathrm{ES}$ & 0.36 & 0.24 & 0.22 & 0.19 & 0.20 & 34.48 & 8.69 & 11.05 & -0.78 \\
\hline FI & 0.57 & 0.41 & 0.30 & 0.24 & 0.25 & 28.48 & 25.92 & 20.31 & -6.05 \\
\hline FR & 0.58 & 0.35 & 0.28 & 0.24 & 0.18 & 39.93 & 18.93 & 13.87 & 24.86 \\
\hline GR & 0.63 & 0.42 & 0.40 & 0.31 & 0.27 & 32.40 & 5.54 & 22.39 & 14.11 \\
\hline $\mathrm{HU}$ & 0.57 & 0.36 & 0.27 & 0.20 & 0.16 & 37.03 & 23.76 & 26.46 & 19.43 \\
\hline IE & 0.67 & 0.54 & 0.39 & 0.30 & 0.30 & 18.52 & 28.50 & 22.17 & 0.04 \\
\hline IS & 0.38 & 0.32 & 0.28 & 0.26 & 0.29 & 16.88 & 12.53 & 5.37 & -10.30 \\
\hline IT & 0.52 & 0.32 & 0.31 & 0.23 & 0.24 & 38.25 & 4.28 & 25.02 & -3.01 \\
\hline $\mathrm{LT}$ & 0.50 & 0.38 & 0.34 & 0.30 & 0.25 & 23.26 & 9.68 & 13.94 & 16.91 \\
\hline $\mathrm{LU}$ & 0.48 & 0.31 & 0.25 & 0.19 & 0.18 & 34.95 & 18.83 & 24.96 & 3.53 \\
\hline LV & 0.47 & 0.37 & 0.33 & 0.30 & 0.28 & 21.73 & 9.79 & 10.44 & 6.64 \\
\hline NL & 0.48 & 0.33 & 0.27 & 0.22 & 0.24 & 30.87 & 18.69 & 16.36 & -5.88 \\
\hline NO & 0.40 & 0.28 & 0.19 & 0.15 & 0.14 & 28.72 & 32.55 & 20.33 & 7.04 \\
\hline PL & 0.63 & 0.37 & 0.31 & 0.31 & 0.26 & 40.65 & 16.54 & 1.98 & 13.35 \\
\hline PT & 0.75 & 0.55 & 0.49 & 0.40 & 0.34 & 27.35 & 9.79 & 19.79 & 13.04 \\
\hline $\mathrm{SE}$ & 0.45 & 0.29 & 0.21 & 0.16 & 0.13 & 34.65 & 29.37 & 20.72 & 18.87 \\
\hline SI & 0.37 & 0.24 & 0.19 & 0.15 & 0.09 & 33.70 & 21.44 & 19.24 & 40.05 \\
\hline SK & 0.31 & 0.18 & 0.15 & 0.13 & 0.12 & 41.01 & 15.52 & 12.81 & 10.06 \\
\hline UK & 0.73 & 0.56 & 0.46 & 0.33 & 0.36 & 23.19 & 16.92 & 28.31 & -7.73 \\
\hline
\end{tabular}

Table 2: GE(2) Inequality Measures and Redistributive Instruments Source: Own calculations based on EU-SILC.

Although we find some hints to country clustering in the case of public pensions and social benefits, we cannot really identify certain welfare state groups with regard to the burden side of the redistributive system. In fact, we find a rather arbitrary ranking of countries. Note, that the redistributive importance of instruments across 
countries does not fully corresponds to the economic weight of these instruments as outlined in the previous Section. On the contrary, this standard approach of redistributional analysis suggests that public pensions are the most important source of inequality reduction, benefits and taxes are on average similarly important, and contributions only lead to significant inequality reduction in a small set of European countries.

As argued above, the results for the redistributive impact of single tax benefit instruments may be sensitive with respect to the assumed sequence of instruments of the income accounting framework. Therefore we also followed the approach suggested by Immervoll et al. (2005) and started for each instrument from the hypothetical situation without the instrument in question (DPI - instrument) and ask by how much inequality is reduced by introducing it. Using this approach instead of the standard approach, however, did not qualitatively change the results. As expected, it only lowers the size of the redistributive effect of benefits.

\subsection{Decomposition Approach}

This section reports the results of the inequality decomposition analysis by factor components as suggested by Shorrocks, i.e. determining the relative inequality contribution $s_{f}$ of the different tax benefit instruments to overall inequality. The results are illustrated in Figure 4. It becomes evident, that the results substantially differ from the previous analysis based on the standard accounting approach. In almost all countries income taxes and social contributions are by far the most important source of income inequality reductions, the contribution of benefits is almost negligible.

The results reveal that interestingly, while taxes and social insurance contributions have a significant equalizing effect in all countries, the effect of social benefits and public pensions is not so clear across countries. Particularly, whereas taxes and contributions reduce income inequality by on average about $30 \%$, social benefits do not seem to have any significant impact on inequality $(<5 \%$ in all countries except Cyprus and Sweden), also the influence of public pensions is comparatively small. In fact, in the majority of countries public pensions have disequalizing effects on the inequality in disposable incomes. On average they increase inequality by $6 \%$. The positive effect of public pensions on inequality is particularly large in Austria, Portugal and Cyprus (>20\%). According to this factor source decomposition approach pensions only have a significant equalizing impact in the Czech Republic, 


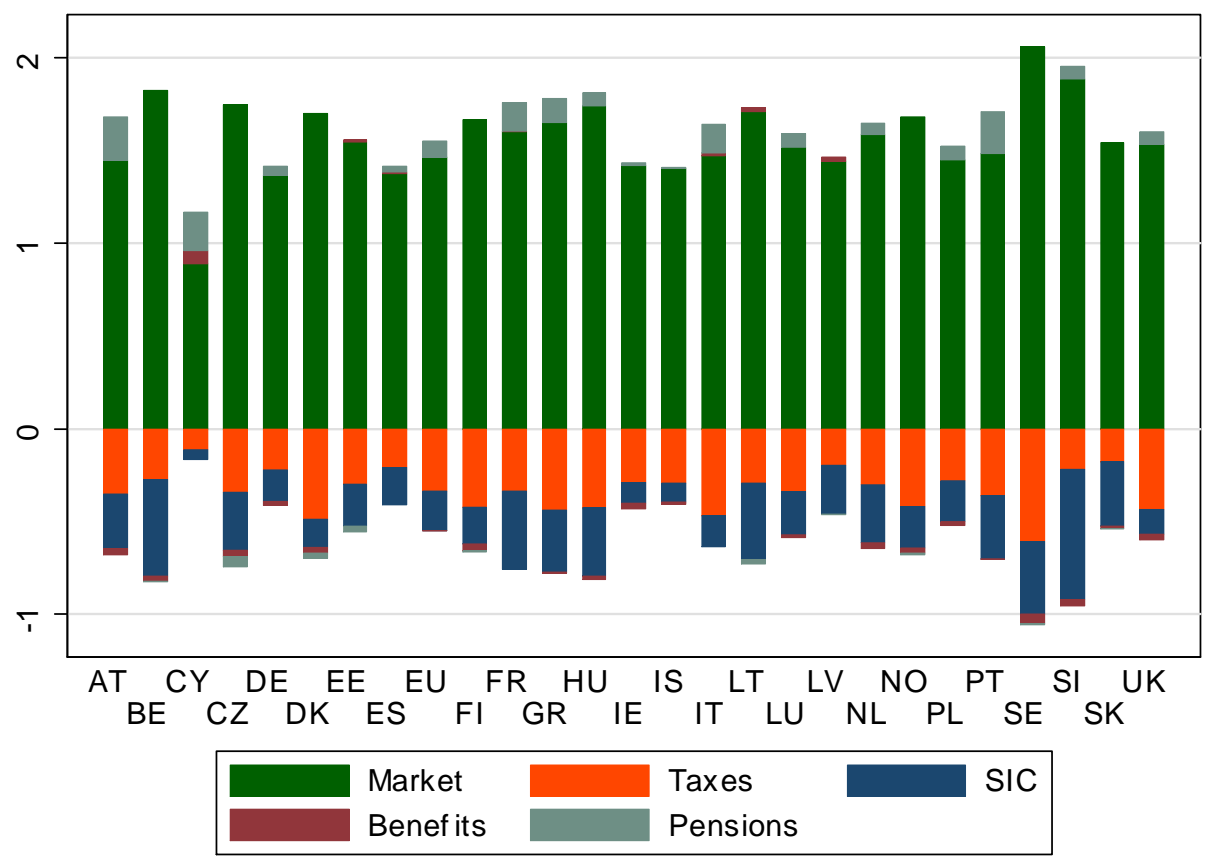

Figure 4: Relative Inequality Contribution of Tax Benefit Instruments Source: Own calculations based on EU-SILC. Note that values above (below) 0 represent a disequalizing (equalizing) impact on income inequality in disposable incomes.

Estonia, Denmark and Lithuania. Also, social benefits positively contribute to the inequality in disposable incomes in at least seven countries. The disequalizing effect is particularly evident in the Baltic States and Cyprus. Social benefits only have noteworthy equalizing effects in the Nordic countries, Slovenia, the Czech Republic, Austria and the Netherlands $(>3 \%)$. With regard to the burden side, the equalizing effect of income taxes is highest in the Nordic Countries. However, in Greece, Italy, Hungary, Poland and the UK taxes also reduce inequality by more then $40 \%$, as suggested by the Shorrocks decomposition method. The equalizing effect of taxes is comparatively small in Cyprus, Latvia and the Slovak Republic. Regarding the inequality contribution of social contributions, the equalizing effect is particularly high in Slovenia, Belgium, France and Latvia (>40\%). The effect is small in Portugal, Cyprus, Iceland, Denmark and the Anglo Saxon countries.

Again, we find some hints for a certain welfare state clustering of countries. Specifically the Nordic countries reveal similarities in the size of the redistributive contribution of the different tax benefit instruments. Also the Anglo-Saxon countries 
and the Baltic states seem to form a rather homogeneous group with regard to the overall inequality contribution of the different tax benefit instruments. The hierarchical cluster analysis in Section 5 will help to identify more exactly groups of countries with respect to the redistributive character of tax benefit instruments.

\subsection{Discussion of the Results}

The two approaches seem to lead to partly contradictory results which would imply very different policy implications - especially with respect to the importance of benefits for redistributing income. Why do we find substantial differences in the redistributive importance of tax benefit instruments across the two approaches, although both approaches are based on the same inequality measure? Both approaches are used in the literature and our results are in line with the respective studies. In fact, studies analyzing the impact of tax benefit instruments based on the standard approach generally find that benefits are the most important source of inequality reduction (e.g., Immervoll et al. (2005), Mahler and Jesuit (2006), Whiteford (2008)). On the other hand, the results of the factor source decomposition (e.g. Jenkins (1995) and Jäntti (1997)) suggest that taxes have a larger contribution to inequality in disposable incomes.

First, an important difference between the two approaches is that the standard approach applies tax benefit instruments sequentially whereas the decomposition approach accounts for them simultaneously. Second, in order to further investigate the sources of the differences, we present the different components which determine the relative inequality contribution of Shorrock's decomposition analysis. As equation 8 suggests, the size of a factor's relative inequality contribution $\left(s_{f}\right)$ depends on its within factor inequality $\left(I_{2}^{f}\right)$, the income share $\left(\mu_{f}\right)$ of the corresponding factor source $f$ and its correlation with disposable income $\left(\rho_{f}\right)$. From Table 3 it becomes obvious that, in those countries where benefits positively contribute to inequality, the correlation coefficient $\rho_{f}$ has a positive sign. The opposite is true for the other countries, where they have an equalizing effect. However, the correlation between disposable income and social benefits is weak. For example, if the EU is seen as a single economic unit, the correlation is almost equal to zero. The correlation between disposable income and public pensions is rather small as well. Taxes, on the other hand show a substantial negative correlation with disposable incomes in all countries. Furthermore, the income share of benefits is smaller than that of taxes 
or contributions in absolute terms. However, the within inequality for benefits (and pensions) is as high as that for tax payments which can be explained due to the large share of people not paying taxes (receiving benefits). The within inequality of social contributions is much lower for most countries and closer to the one of factor income. This further break-down of the decomposition results reveals, that the negligible effect of social benefits on income inequality is due to the effect that they are hardly correlated with income in most countries. Only the liberal welfare states of Ireland and the UK that mainly rely on means-tested benefits show a significant negative correlation of benefits with disposable income (together with a low factor share).

Our finding that benefits account for a positive or negligible share of total inequality in most countries - as revealed by the inequality decomposition above is perfectly consistent with our earlier finding that benefits on the whole reduced income inequality - as revealed by the standard approach to distributional analysis in Section 4.1. In a related context, Stark et al. (1986) illustrate similar results with a simple chemical experiment in which a highly concentrated solution is mixed with a less (but still positively) concentrated one. Although the resulting mixture will be less concentrated than the original, the added solution is still responsible for a part of the concentration of the final mix. Therefore, unless the correlation between benefits and disposable incomes is negative, benefits will always account for a non-negative share of total income inequality. To put it more technically, in order to find an unique decomposition rule for any inequality measure, Shorrocks (1982) imposed the assumption of the normalization of equal factor distributions. This restriction implies that according to Shorrocks decomposition method, equally distributed lump sum transfers do not contribute to overall inequality. However, most aggregate inequality measures satisfy the axiom that such equally distributed transfers (i.e. which are relatively higher for lower incomes) reduce aggregate inequality whereas proportional transfers do not change it. This axiom also holds for the GE(2) measure. Within the standard approach, therefore, equally distributed transfers imply an inequality reduction. In the decomposition approach, such transfers have a zero inequality contribution because their correlation with disposable income is zero. In this framework, an income component has to be higher in absolute terms for lower incomes in order to achieve a negative contribution to overall inequality. Therefore, these two different normative foundations of the two approaches are to some extent responsible for the differing results. 
These differing results have important implications for the policy conclusions. It would be wrong to conclude from their positive contribution to overall inequality in the Shorrocks approach that benefits increase inequality and should therefore, for instance, be abolished. This positive contribution has to be interpreted as the contribution of the components of the tax benefit system to overall inequality (like the different solutions to the mixture in the chemical example) but not as the effect of a change in this instrument. Abolishing the benefits would increase inequality, as shown by the sequential approach. Nonetheless, from the decomposition approach and due to the rather weak correlation of benefits and disposable income it can be learned that benefits seem to have other objectives than income redistribution (e.g. support of families with children or elderly people).

$>$ From a policy perspective, it is important to take into account the results from both approaches. The standard approach (and the literature applying it) suggests that benefits are the most important source of income redistribution. However, the decomposition approach qualifies this view by taking the (weak) correlation into account and therefore highlights the different functions of taxes and benefits for redistributing income. It is interesting to see how different countries use these different measures. Therefore, in the next step, we perform a cluster analysis to classify countries with respect to similarities in their tax benefit systems.

\section{Cluster Analysis}

As outlined above, we are particularly interested in how the new member states can be integrated in the existing welfare state typology when focusing on outcome variables in terms of the redistributive effects of different tax benefit systems. Therefore, we conduct a hierarchical cluster analysis to group countries that have similar characteristics across a set of variables. When performing a cluster analysis, a number of technical decisions have to be made. First, all variables have been standardized from 0 to 1 using z-scores, to prevent that the results are driven by large absolute values of some variables. Our method of grouping the countries is the common Ward's linkage, which combines such clusters which minimally increase the squared sum of errors. Our results will be illustrated in so-called dendrograms, which graphically present the information concerning which observations are grouped together at various levels of (dis)similarity. At the bottom of the dendrogram, each observation is 
considered as its own cluster. Vertical lines extend up for each observation, and at various (dis)similarity values these lines are connected to the lines from other observations with a horizontal line. The observations continue to combine, until, at the top of the dendrogram, all observations are grouped together. The height of the vertical lines and the range of the (dis)similarity axis give visual clues about the strength of the clustering. In our case, the measure for the distance between cases is the common 'squared Euclidean'. Generally, long vertical lines indicate more distinct separation between groups, short lines more similarity, respectively. ${ }^{7}$

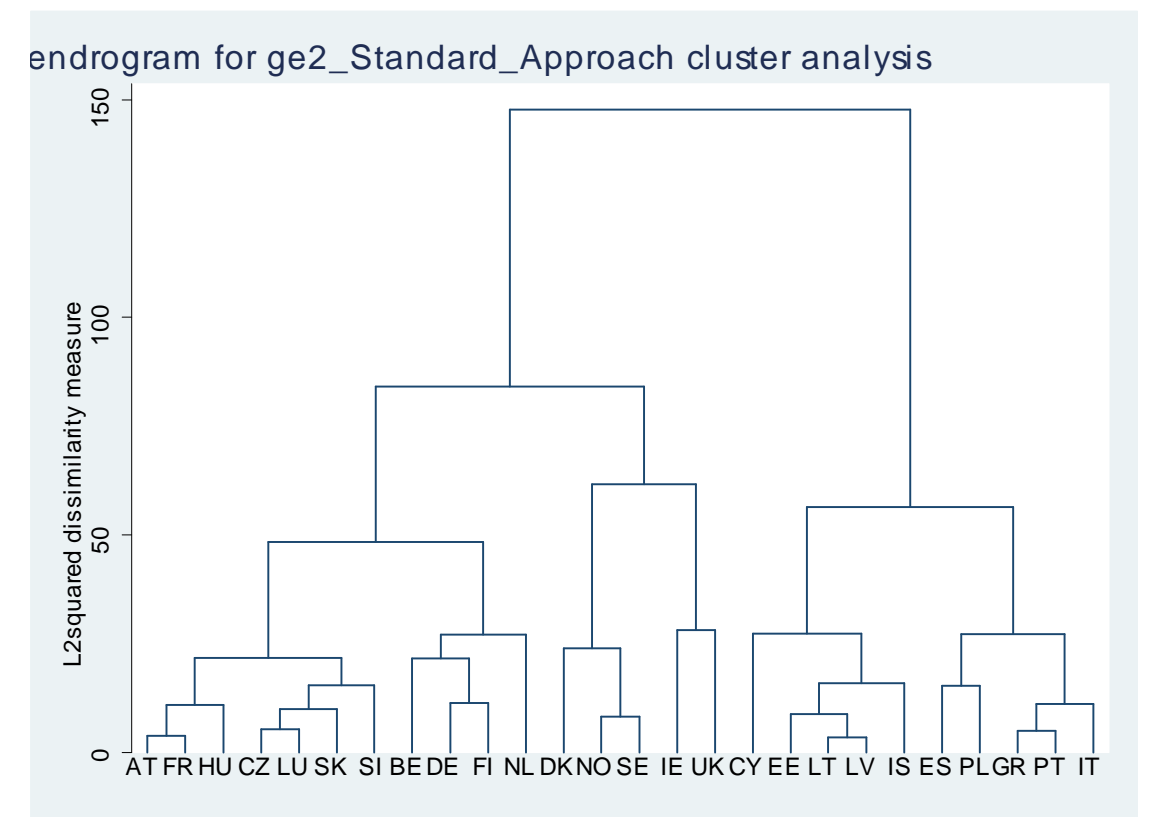

Figure 5: Cluster Analysis of Redistributive Effects based on Standard Approach Source: Own calculations based on EU-SILC.

First, we perform a cluster analysis on the basis of the redistributive effects of tax benefit instruments, as computed by the \% change in GE(2) combined with the importance of pre-government income inequality and the economic weight of the different components. The dendrogram is illustrated in Figure 5. To the very right of the dendrogram we see the Southern European countries (IT, PT, ES, GR) and Poland which group together with the Baltic countries (LT, LV, EE), Iceland and Cyprus. As illustrated by a comparatively high dissimilarity measure, this group of countries

\footnotetext{
${ }^{7}$ Note that the general clustering results presented here are robust to different linkage or dissimilarity measure specifications. We report the results for the most common combination found in the literature.
} 
is rather distinct from the countries which are placed at the left and the middle of the dendrogram. However, these groups can again be divided into two rather separated subgroups. At the left we basically find the Continental countries (AT, FR, LU, BE, DE, NL) which join a couple of Eastern European countries (CZ, SI, SK). In the middle, we see the Nordic countries (DK, SE, NO) and the Anglo-Saxon countries. Therefore from this hierarchical cluster analysis based on the redistributive effects of tax benefit instruments measured by the standard accounting approach, the new Eastern European member states do not form a clearly distinguished group from the traditional European welfare states. Instead, the Baltic states show similar characteristics as the Southern European countries and the Central Eastern European countries seem to perform similar to the Continental countries.

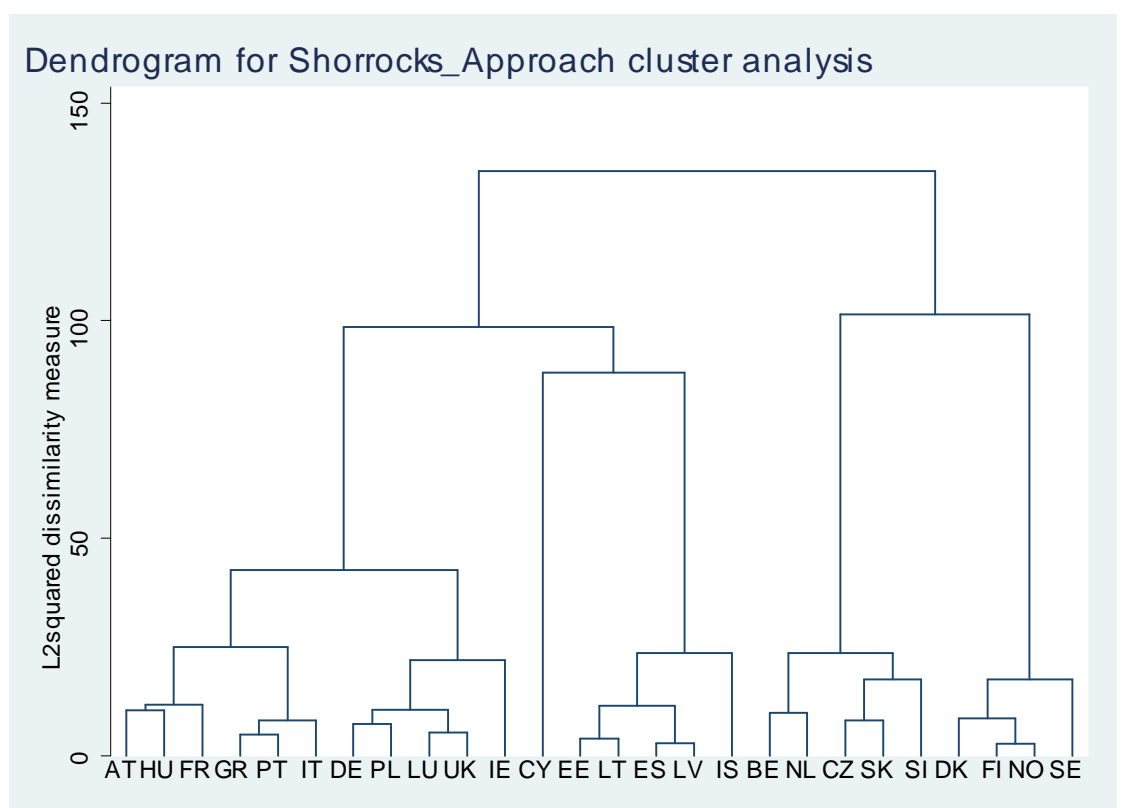

Figure 6: Cluster Analysis of Redistributive Effects based on Decomposition Approach

Source: Own calculations based on EU-SILC.

Second, we perform the cluster analysis on the basis of the inequality contribution of the different tax benefit instruments as computed with the Shorrocks factor source decomposition approach. Again we also control for the importance of the pre-government income distribution and the economic weight of the different components. Figure 6 shows the dendrogram which presents the outcomes of this cluster analysis. Now we see the Nordic countries on the very right which form a rather 
distinct group. This group is then joined by the Continental countries Belgium and the Netherlands and the Eastern European countries Slovak and Czech Republic and Slovenia. On the left we then find a rather mixed group of Continental, Southern and Anglo-Saxon countries, joined by Hungary and Poland. Then, in the middle we find the Baltic countries, joined by Spain, Iceland and later Cyprus. Overall, the cluster analysis based on the Shorrocks approach reveals the Baltic countries as a rather distinguished group, still with similarities to at least two Southern European countries (CY, ES). However, the Central Eastern European countries again seem to very naturally group together with the traditional Western European welfare states.

To sum up, the welfare state clustering is robust for the Western European countries. When using economic outcome indicators based on micro data, the welfare state typology derived from the input oriented macro data approach of the political sciences literature is confirmed. The new member states, however, do not form their own cluster as suggested, e.g., by Deacon (2000), Ferge (2001) or Fenger (2007). Our analysis confirms the view of Esping-Andersen (1996) that the differences between these countries and the traditional welfare states are only of transitional nature. Nonetheless, within the group of new member states, the Baltic countries form a rather homogenous group which is completely in line with what one would expect given the design of their flat tax systems.

\section{Conclusion}

The enhancement of economic and social cohesion is a key target of EU policies. Nonetheless, the descriptive evidence suggests that there are sizeable differences across EU member states in the levels of within country income inequality - especially since the recent enlargement towards Eastern Europe. This holds true for the inequality in disposable incomes as well as the inequality in pre-tax incomes, hinting at the substantial variety in the national income tax benefit systems. From a policy perspective, differences in the inequality of disposable incomes and, in particular, factors explaining these differences, including the tax and transfer system, are of particular interest in order to evaluate the different welfare state designs of European countries. In this paper, we have evaluated the impact of different tax benefit instruments (income taxes, social contributions, pensions, transfers) on income inequality and specifically ask the question if the role of instruments differs 
across countries.

Our results reveal that according to the GE(2) standard accounting approach, benefits are the most important source of inequality reduction in most European tax and transfer systems, taxes are less important. Also, public pensions play an important role in lowering the inequality in disposable incomes, when comparing the hypothetical situation without public pensions. The factor source decomposition approach as suggested by Shorrocks, however, leads to very different results: taxes and social insurance contributions are by far the most important contributors to income inequality and the contribution of benefits is close to zero. Public pensions even positively contribute to the inequality in disposable incomes in most countries.

An explanation for these partly contradictory results lies in the different normative focus of the two approaches as discussed in Section 4.3. Furthermore, it can be argued that many transfers have purposes other than income distribution. Whereas taxes and social contributions are clearly correlated with income, transfers have a much less clear effect on the income distribution, but they address other issues. This is clearly illustrated by the almost negligible correlation between social benefits and disposable income. A clear negative correlation to disposable income can be found only for some specific transfers like means-tested benefits for the long term unemployed and benefits for social exclusion; but these are only a small part of overall transfers in most countries.

Furthermore, we performed a hierarchical cluster analysis to see in how far the redistributive importance of tax benefit instruments differs across countries and particularly, how the new member states integrate in the group of traditional European welfare states. First we find that although the country grouping slightly differs across our two approaches, the overall results are quite robust. With regard to Western Europe, we basically observe the 'typical' welfare state clustering as suggested by Esping-Andersen (1990) and later modified by Ferrera (1996). Particularly the Nordic countries reveal very similar characteristics with regard to the redistributive effects of their tax benefit instruments in both approaches. Also the Continental and Southern European countries group together. However, as opposed to large parts of the welfare state literature, we do not find the Eastern European countries to be a clear distinguished group when we cluster according to the redistributive importance of tax benefit instruments. This confirms the view of Esping-Andersen (1996) that differences between East and West are only due to the transition period. Instead, the Central Eastern European countries seem to naturally group together 
with the traditional Continental Western European welfare states. The Baltic flat tax countries are distinct from the other countries, but as the cluster analysis shows, they still have some similarities to some Southern European countries. This finding seems plausible, since both, the Southern and Baltic countries can be characterized by rather small welfare states compared to other European countries.

Note, however, that there are limitations to our analysis. First and most importantly, the analysis only assesses the direct effects of taxes and transfers on household incomes. But, the tax system has both a direct effect on the post-government income distribution and an indirect effect as it may also influence the pre-tax income distribution. However, any behavioral effects caused by redistributive policies are not captured. Second, the study is static which means that the distribution of lifetime incomes is not taken into account. Third, due to data limitations, we cannot account for in-kind transfers or indirect taxes which have different distributional impacts in different countries. This should be subject of future research when comparative data on these elements become available. 


\section{References}

Anand, S. and Segal, P. (2008). What Do We Know about Global Income Inequality?, Journal of Economic Literature 46: 57-94.

Arts, W. A. and Gelissen, J. (2002). Three worlds of welfare capitalism or more? A state-of-the-art report, Journal of European Social Policy 12(2): 137-158.

Atkinson, A. B. (1970). On the measurement of inequality, Journal of Economic Theory 2: 244-263.

Cowell, F. and Kuga, K. (1981). Additivity and the entropy concept: An axiomatic approach to inequality measurement, Journal of Economic Theory 25: 131-143.

Dahlby, B. G. (1987). Interpreting inequality measures in a Harsanyi framework, Theory and Decision 22: 187-202.

Deacon, B. (1993). Developments in East European Social Policy, in C. Jones (ed.), New Perspectives on the Welfare State in Europe, London: Routledge.

Deacon, B. (2000). Eastern European Welfare States: The Imppact of the Politics of Globalization, Journal of European Social Policy 10: 146-161.

Esping-Andersen, G. (1990). The Three Worlds of Welfare Capitalism, Princeton University Press.

Esping-Andersen, G. (1996). Welfare States in Transition. National Adaptions in Global Economies, in G. Esping-Andersen (ed.), After the Golden Age? Welfare State Dilemmas in a Global Economy, London: Sage.

Fenger, H. J. M. (2007). Welfare Regimes in Central and Eastern Europe: Incorporating Post-Communist Countries in a Welfare Regime Typology, Contemporary Issues and Ideas in Social Sciences $\mathbf{3}$.

Ferge, Z. (2001). Globalization and European Welfare States: Challenges and Change, in B. Sykes, B. Palier and M. Prior (eds), Welfare and 'Ill-fare' Systems in Central-Eastern Europe, Basingstoke: Palgrave.

Ferrarini, T. and Nelson, K. (2003). Taxation of Social Insurance and Redistribution: A Comparative Analysis of Ten Welfare States, Journal of European Social Policy 13: 21-33. 
Ferrera, M. (1996). The 'Southern Model' of Welfare in Social Europe, Journal of European Social Policy 6 (1): 17-37.

Frässdorf, A., Grabka, M. M. and Schwarze, J. (2008). The Impact of Household Capital Income on Income Inequality - A Factor Decomposition Analysis for Great Britain, Germany and the USA, IZA Discussion Paper No. 3492.

Harsanyi, J. C. (1953). Cardinal utility in welfare economics and in the theory of risk-taking, Journal of Political Economy 61(5): 434-438.

Harsanyi, J. C. (1977). Morality and the theory of rational behavior, Social Research 44: $623-656$.

Immervoll, H., Levy, H., Lietz, C., Mantovani, D., O’Donoghue, C., Sutherland, H. and Verbist, G. (2005). Household Incomes and Redistribution in the European Union: Quantifying the Equalising Properties of Taxes and Benefits, Economic Series 184 .

Jenkins, S. P. (1995). Accounting for Inequality Trends: Decomposition Analyses for the UK, 1971-86, Economica 62: 29-63.

Jäntti, M. (1997). Inequality in Five Countries in the 1980s: The Role of Demographic Shifts, Markets and Government Policies, Economica 64: 415-40.

Kolm, S.-C. (1969). The Optimal Production of Social Justice, St. Martin's Press, New York and Macmillan, London, pp. 145-200.

Maasoumi, E. (1999). Empirical Analyses of Inequality and Welfare, in M. H. Pesaran and P. Schmidt (eds), Handbook of Applied Econometrics Volume II: Microeconomics, Blackwell Publishing, Oxford, chapter 5, pp. 202-245.

Mahler, V. A. and Jesuit, D. K. (2006). Fiscal Redistribution in the Developed Countries: New Insights from the Luxembourg Income Study, Socio-Economic Review 4: 483-511.

Mitchell, D. (1991). Income Transfers in Ten Welfare States, Aldershot, Avebury.

Shorrocks, A. (1980). The Class of Additively Decomposable Inequality Measures, Econometrica 48: 613-625. 
Shorrocks, A. (1982). Inequality Decomposition by Factor Components, Econometrica 50: 193-211.

Shorrocks, A. (1983). The Impact of Income Components on the Distribution of Family Incomes, Quarterly Journal of Economics 98: 311-326.

Stark, O., Taylor, E. T. and Yitzhaki, S. (1986). Remittances and Inequality, The Economic Journal 96: 722-740.

Theil, H. (1967). Economics and Information Theory, North Holland, Amsterdam.

Whiteford, P. (2008). How Much Redistribution do Governments Achieve? The Role of Cash Transfers and Household Taxes, Growing Unequal: Income Distribution and Poverty in OECD Countries, OECD, Paris. 